\title{
Schedule-induced polydipsia, schedule-induced drinking, and body weight
}

\author{
J. D. KEEHN \\ York University, Downsview, Ontario M3J 2R7, Canada
}

\begin{abstract}
Volumes and frequencies of schedule-induced drinks were studied in three well trained rats as body weights rose from $80 \%$ to over $90 \%$ of normal. An inverse relationship between drinking and body weight obtained. It occurred mostly because draught size diminished as body weight increased, but also because occasions of drinking became less frequent.
\end{abstract}

Schedule-induced polydipsia is a condition of overdrinking generated by spaced feeding of hungry animals. Two recent major reviews (Falk, 1977; Staddon, 1977) both stress food deprivation (or hunger motivation) as a major determinant of the phenomenon and offer several lines of supporting evidence, including the inverse relationship between schedule-induced polydipsia and body weight reported by Falk (1969). The present study extends Falk's finding and adds an additional datum to differentiate schedule-induced polydipsia, which is measured by volume of fluid intake (draught quantity), from schedule-induced drinking, which is measured by occasions that pellets are followed by drinks (draught frequency). The question addressed is: does body weight affect draught quantity, draught frequency, or both?

\section{METHOD}

\section{Subjects}

Three male Wistar rats obtained from High Oak Ranch, Ontario, were used. Their free-feeding weights at 120 days of age were 486 (S4), 468 (S5), and $486 \mathrm{~g}$ (S6). They were reduced to $80 \%$ of those weights for baseline measurements; running weights during the experiment appear below. The subjects were housed in individual cages with water freely available at all times.

\section{Apparatus}

Experimental sessions were run in standard $11.5 \times 9.5 \times$ 7.5 in. $(29 \times 23.5 \times 19 \mathrm{~cm})$ Grason-Stadler two-bar rat chambers (Type E $3125 \mathrm{~B}$ ) with reinforcement magazines that delivered 45-mg Noyes rat pellets as scheduled. In each box, the left-hand bar was removed and its housing was covered with a metal plate mounted flush with the wall. A force of $20 \mathrm{~g}(.19 \mathrm{~N})$ on the remaining bar activated electromechanical scheduling and recording equipment located in an adjoining room.

A water bottle was attached to the outside of each chamber door such that the outlet tube was 2 in. $(5 \mathrm{~cm})$ above floor level and $3.5 \mathrm{in} .(9 \mathrm{~cm})$ from the wall containing the response bar and food magazine. Barpresses and licks were recorded on Sodeco counters, and daily water consumption was measured with graduated flasks. All sessions were conducted with the

Supported by an Atkinson College research grant. Reprints may be obtained from the author at Atkinson College, York University, Downsview, Ontario M3J 2R7, Canada. experimental chambers enclosed in sound-attenuating ventilated boxes.

\section{Procedure}

Each subject was trained to barpress for food reinforcement with a continuous reinforcement schedule that was adjusted to a fixed-interval (FI) 60 -sec schedule in a single preexperimental session. Thereafter, for 16 sessions, barpresses were reinforced at fixed intervals of $60 \mathrm{sec}$. In Session 17, the number of responses required for reinforcement at the end of every $60-\mathrm{sec}$ interval was adjusted from 1 to 5 to 10 . From Session 18 to the end of the experiment, only the 10 th response after the end of each 60-sec interval was reinforced (tandem FI 60/ FR 10). Sessions lasted $90 \mathrm{~min}$ or until 60 reinforcers were obtained, whichever came first.

Until Session 50, subjects' body weights were maintained close to $80 \%$ of free-feeding values (S4, $389 \mathrm{~g}$; S5, $374 \mathrm{~g}$; S6, $389 \mathrm{~g}$ ). After this, for 12 sessions, body weights were elevated by means of supplementary postsession feedings such that terminal running weights were 451 (S4), 453 (S5), and $452 \mathrm{~g}$ (S6). These values are $93 \%, 97 \%$, and $93 \%$ of the weights of the respective animals at the beginning of the experiment. Body weights, volumes of fluid consumed, numbers of barpresses, and durations of fixed-ratio (FR) 10 runs were recorded on Sessions 51-62. Percentages of pellets followed by drinks were computed from cumulative records obtained on Gerbrands cumulative recorders.

\section{RESULTS}

All subjects developed the typical eat-drink pattern of schedule-induced drinking within the first 16 sessions and maintained it for the rest of the baseline period (up to Session 50 ). In the three sessions at $80 \%$ body weight immediately before weights were permitted to rise, S4, S5, and S6 consumed averages of 38.0, 28.3 , and $38.7 \mathrm{ml}$ of water, respectively. In these sessions, the respective animals drank after $100 \%$, $95 \%$, and $100 \%$ of the pellets they obtained. As body weights rose across Sessions 51-62, so water intakes fell. Figure 1 shows that a roughly linear decline in fluid intake accompanied a roughly linear rise in body weight over these sessions. Rank-order correlations (rho) between body weights and volumes of water consumed for S4, S5, and S6, respectively, were $-.88,-.91$, and -.89 . These values are inflated, as the measures for each animal are not independent, but, over the group of three animals, mean water intake at the four lowest 

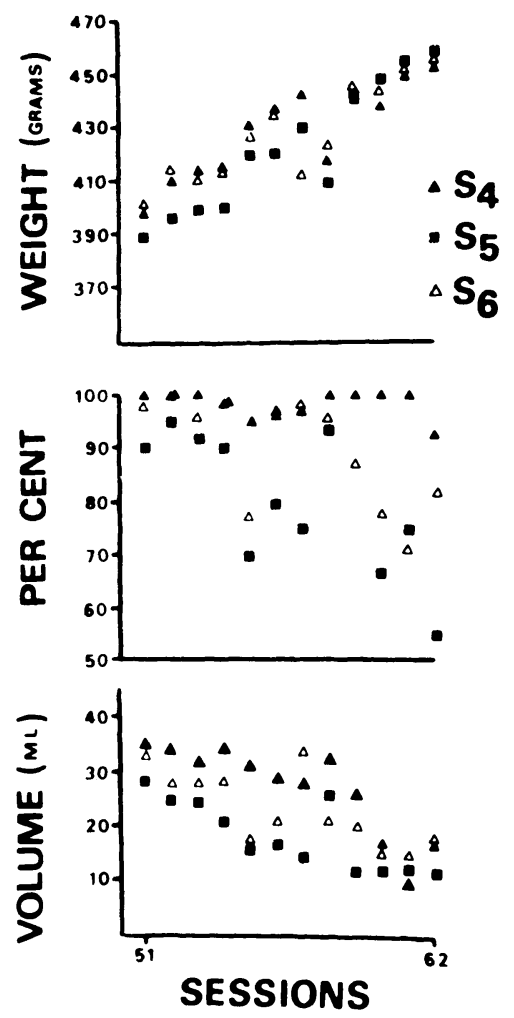

Figure 1. Body weight, percentage of pellets followed by drinks, and volume of fluid consumed per session by the individual subjects.

weights $(29.7 \mathrm{ml})$ exceeded the mean water intake at the four highest body weights $(16.75 \mathrm{ml})$ at the .01 confidence level $[t(2)=27.96]$.

The manner in which drinking declined with rising body weight differed among the animals. Figure 1 shows that S4 drank after nearly $100 \%$ of the pellets it consumed, even though its fluid intake steadily declined from Session 51 to Session 61. The animal must therefore have consumed less water after each pellet as its body weight rose. S5, on the other hand, drank after fewer and fewer pellets as its body weight increased. The third animal performed midway between the others: Up to Session 57, it behaved like S4 by drinking after most pellets, but thereafter, it followed S5 in drinking after fewer pellets as body weight increased.

Mean draught sizes (expressed as milliliters per drink) and draught frequencies (expressed as percentages of pellets followed by drinks) arranged in descending order of body weight are shown separately for each animal in Table 1. Rank-order correlations between body weight and draught size for S4, S5, and S6, respectively, were $-.87,-.91$, and -.84 . In each case, comparable correlations between body weight and draught frequency were lower than those between weight and size (see Table 1).

Table 2 contains total barpresses per animal per session across Sessions 51-61 (data for Session 62 were not collected), and mean times taken by each animal in each session to perform the 10-response fixed ratio. Except on three occasions when the animals failed to receive 60 scheduled pellets in a session, ratio durations showed little variability as body weight changed. This confirms the known resistance of ratiocontrolled behavior to experimental manipulation (Sidman, 1961). The relationship between body weight and total responses per session differed from animal to animal: Rank-order correlations for S4 and S6 were -.62 and -.63 , respectively, but it was -.07 for S5. Thus S5, the subject that persisted least in postpellet drinking (drink frequency) as it became heavier, was also the only animal for which barpress rate and body weight were uncorrelated. This animal never failed to receive all the pellets available in a session; S4 failed twice (Sessions 60 and 61) and S6 failed once (Session 55). On all other occasions, all animals rapidly secured food pellets as soon as they were scheduled.

Table 1

Draught Frequency (F) in Percent, Mean Draught Size (S) in Milliliters, and Body Weight (W) in Grams

\begin{tabular}{|c|c|c|c|c|c|c|c|c|}
\hline \multicolumn{3}{|c|}{ S4* } & \multicolumn{3}{|c|}{$\mathrm{S} 5 * *$} & \multicolumn{3}{|c|}{ S6† } \\
\hline W & $\mathrm{S}$ & F & W & $\mathrm{S}$ & $\mathrm{F}$ & W & $\mathrm{S}$ & $\mathrm{F}$ \\
\hline 451 & .25 & 100 & 453 & .27 & 75 & 452 & .33 & 71 \\
\hline 442 & .49 & 97 & 448 & .29 & 67 & 446 & .38 & 87 \\
\hline 440 & .43 & 100 & 444 & .26 & 78 & 444 & .32 & 78 \\
\hline 438 & .38 & 100 & 431 & .31 & 75 & 435 & .36 & 97 \\
\hline 437 & .50 & 97 & 421 & .35 & 80 & 426 & .37 & 77 \\
\hline 431 & .54 & 95 & 421 & .38 & 70 & 424 & .37 & 95 \\
\hline 416 & .55 & 100 & 410 & .46 & 93 & 415 & .47 & 100 \\
\hline 414 & .58 & 98 & 401 & .39 & 90 & 414 & .48 & 98 \\
\hline 414 & .53 & 100 & 400 & .43 & 92 & 412 & .48 & 98 \\
\hline 411 & .57 & 100 & 397 & .44 & 95 & 411 & .49 & 96 \\
\hline 400 & .58 & 100 & 390 & .52 & 90 & 401 & .56 & 98 \\
\hline
\end{tabular}

*Rank-order correlation (rho) for weight by size $=-87$, for weight by frequency $=-.02$. $\quad * *$ Rho for weight by size $=-.91$, for weight by frequency $=-.72$. tRho for weight by size $=-.84$, for weight by frequency $=-.71$.

Table 2

Number (N) of Barpresses and Mean FR 10 Duration (D) per Session in Seconds

\begin{tabular}{|c|c|c|c|c|c|c|}
\hline \multirow[b]{2}{*}{ Session } & \multicolumn{2}{|c|}{ S4 } & \multicolumn{2}{|c|}{ S5 } & \multicolumn{2}{|c|}{ S6 } \\
\hline & $\mathrm{N}$ & D & $\mathbf{N}$ & D & $\mathrm{N}$ & $\mathrm{D}$ \\
\hline 51 & 1509 & 3.7 & 2687 & 2.7 & 2360 & 3.0 \\
\hline 52 & 1353 & 4.6 & 2377 & 2.6 & 1909 & 3.0 \\
\hline 53 & 1359 & 5.1 & 1810 & 2.3 & 1937 & 3.1 \\
\hline 54 & 1531 & 3.5 & 1974 & 2.8 & 1778 & 3.0 \\
\hline 55 & 1279 & 4.8 & 2280 & 3.2 & 1406 & $10.3^{*}$ \\
\hline 56 & 1180 & 5.3 & 1970 & 3.1 & 1650 & 3.3 \\
\hline 57 & 1204 & 5.0 & 2683 & 2.8 & 1676 & 3.0 \\
\hline 58 & 933 & 4.9 & 2026 & 2.8 & 1363 & 3.5 \\
\hline 59 & 1421 & 4.8 & 2217 & 2.4 & 1688 & 3.8 \\
\hline 60 & 637 & $11.3^{*}$ & 2054 & 3.0 & 1487 & 4.2 \\
\hline 61 & 474 & $10.0^{*}$ & 2122 & 3.7 & 1530 & 3.9 \\
\hline
\end{tabular}

*Subject failed to secure all 60 pellets scheduled for the session. 


\section{DISCUSSION}

A finding by Falk (1969) implicates hunger motivation as a determinant of schedule-induced polydipsia. He found little effect of body weight on polydipsia water intake by well trained rats whose weights were manipulated between $80 \%$ and $95 \%$ of free-feeding levels, but, at higher body weights, up to $105 \%$ of normal, schedule-induced water intakes fell. As feeding could be sporadic at these body weights, the relationship between weight and water intake need not involve hunger motivation directly, however, because schedule-induced drinking declines when interpellet intervals rise above about 2 min (Keehn \& Colotla, 1971), regardless of body weight.

The present results extend those of Falk $(1969,1977)$ by showing a greater range of body weight over which weight and schedule-induced fluid intake are inversely related (see also Freed \& Hymowitz, 1972, for a similar result during polydipsia acquisition). In our case, interpellet interval variations cannot explain the results, as these intervals rarely exceeded $70 \mathrm{sec}$ ( $60 \mathrm{sec}$ plus the time to make 10 barpresses). Our animals differed in the ways that they reduced fluid intakes as body weights rose, but, apart from S4, who drank after almost $100 \%$ of food pellets except at its highest body weight, scheduleinduced drinks generally declined as body weights rose. With S4, increasing body weight only affected draught size, but with the other subjects, reductions in draught frequencies also accounted for reductions in fluid intakes. However, with all subjects, draught frequency was less highly related to body weight than was draught size.

\section{REFERENCES}

Falk, J. L. Conditions producing psychogenic polydipsia. Annals of the New York Academy of Sciences, 1969, 157, 569-593.

FALK, J. L. The origin and functions of adjunctive behavior. Animal Learning \& Behavior, 1977, 5, 325-335.

FreEd, E. X., \& Hymowitz, N. Effects of schedule, percent body weight and magnitude of reinforcer on acquisition of scheduleinduced polydipsia. Psychological Reports, 1972, 31, 95-101.

KeEHN, J. D., \& Colotra, V. A. Schedule-induced drinking as a function of interpellet interval. Psychonomic Science, 1971, 23, 69-71.

Sidman, M. Tactics of scientific research. New York: Basic Books, 1961.

Staddon, J. E. R. Schedule-induced behavior. In W. K. Honig \& J. E. R. Staddon (Eds.), Handbook of operant behavior, New York: Prentice-Hall, 1977.

(Received for publication November 1, 1978.) 